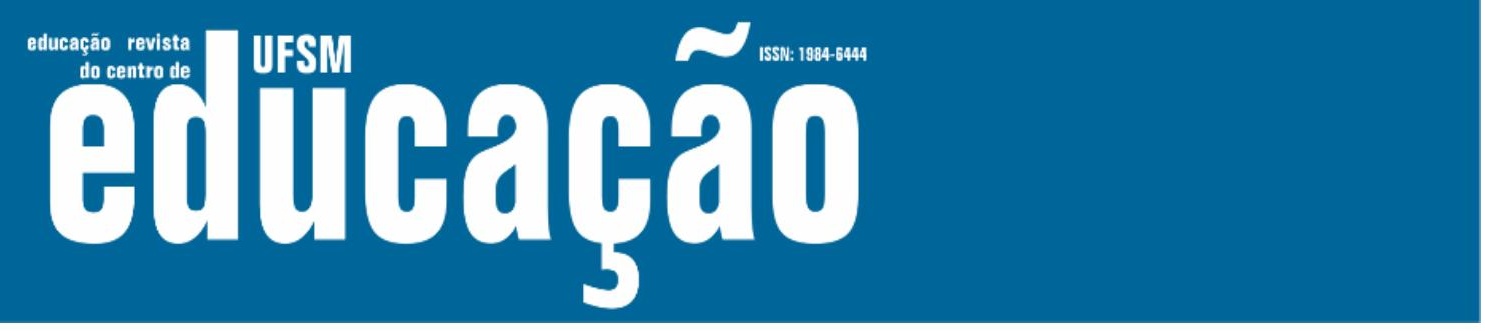

ISSN: 1984-6444 | http://dx.doi.org/10.5902/1984644440318

\title{
Relações de gênero, renda e trabalho em microdados sobre formação inicial de professores/as no Brasil: uma análise multivariada
}

Gender relations, income, and work on microdata about initial teacher training in Brazil: a multivariate analysis

Daniel de Freitas Nunes

Professor da Educação Básica, Científica e Tecnológica do Instituto Federal Goiano, Campos Belos, Goiás, Brasil.

daniel.freitas@ifgoiano.edu.br - https://orcid.org/0000-0002-7468-0390

Etiene Fabbrin Pires Oliveira

Professora doutora na Universidade Federal do Tocantins, Palmas, Tocantins, Brasil. etienefabbrin@uft.edu.br - https://orcid.org/0000-0002-6062-8014

Marcos Felipe Gonçalves Maia

Doutorando em Educação na Universidade Federal da Paraíba, João Pessoa, Brasil.. marcosmaia@uft.edu.br - https://orcid.org/0000-0001-8118-6211

Recebido em 01 de outubro de 2019

Aprovado em 14 de maio de 2020

Publicado em 18 de novembro de 2020

\section{RESUMO}

O presente artigo apresenta dados relativos as relações e desigualdade de gênero em cursos de formação inicial de professores no Brasil buscando verificar em uma perspectiva multivariada as nuances desta desigualdade. Neste sentido, buscou-se, a partir do emprego de técnicas de análise multivariada de dados, verificar o impacto da questão de gênero em diferentes indicadores socioeconômicos de 197.625 estudantes de licenciatura no Brasil, compreendendo 78.088 alunos de instituições públicas e 119.537 de privadas, partindo-se da diferenciação teórica dos conceitos de sexo e gênero, partindo-se da premissa de que feminino e masculino dividem a amostra trabalhada pelo caractere do sexo biológico ao mesmo tempo em que o conceito de gênero é aqui compreendido como um instrumento de sedimentação da dominação do masculino sobre o feminino. Metodologicamente, o estudo caracterizase como um estudo quali/quantitativo e emprega a técnica estatística multivariada de Análise de Correspondência (AC). Conclusivamente, discute-se que desigualdade de gênero nos cursos de formação de professores no Brasil vai além da desigualdade direta, isto é, o desequilíbrio no número de matriculados por sexo, refletindo também em desigualdade de renda, trabalho e condições para estudo.

Palavras-chave: Formação de professores; Gênero; Desigualdade. 


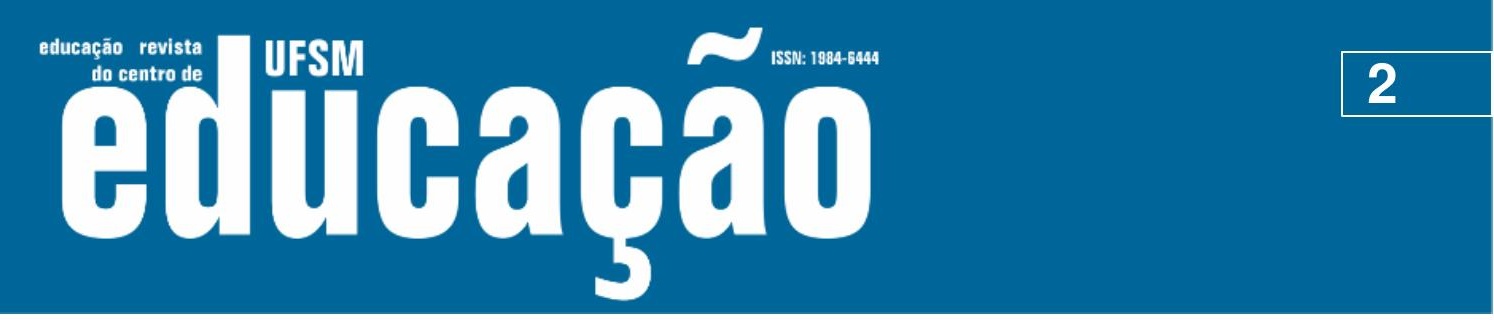

ISSN: 1984-6444 | http://dx.doi.org/10.5902/1984644440318

\section{ABSTRACT}

This paper presents some data on gender relations and inequality in initial teacher training courses in Brazil seeking to verify in a multivariate perspective the nuances of this inequality. By the way, it was sought, based on the use of multivariate data analysis techniques, to verify the impact of the gender question on different socioeconomic indicators of 197.625 undergraduate teacher training students in Brazil, comprising 78. 088 students from public institutions and 119.537 from private institutions. The analytical perspective applied is based on the theoretical differentiation of the concepts of sex and gender, starting from the premise that the feminine and masculine divide the sample worked by the character of the biological sex at the same time that the concept of gender is understood here as an instrument of sedimentation of domination from the masculine to the feminine. Methodologically, the study is characterized as a qualitative / quantitative study and employs the multivariate statistical technique of Correspondence Analysis (CA). conclusively, it is argued that gender inequality in teacher training courses in Brazil goes beyond direct inequality, that is, the imbalance in the number of students enrolled by sex, also reflecting inequality of income, work and conditions for study.

Keywords: Teacher training, Gender, Inequality.

\section{Introdução}

Apesar da latência do tema e do crescimento observado na discussão da questão de gênero no âmbito do trabalho feminino na sala de aula na década de 1990, Vianna (2002) nos lembra que raras exceções, as pesquisas sobre os meandros da sala de aula insistiam em uma retórica na qual a escola era vista quase que exclusivamente como um espaço onde as relações de classe preponderavam sobre quaisquer outras, desconsiderando, portanto, questões como gênero e etnia/raça.

De todo modo, é recorrente na literatura que trata da formação ou identidade docente a partir de então (ENGUITA, 1991; ROSEMBERG,AMADO, 1992; APPLE, 1996; VIANNA, 2002; FONTANA, 2005), a discussão de que este campo profissional se constituiu ao longo das décadas do século XX, em um espaço predominantemente feminino apoiado em um papel de gênero depositado nas mulheres, isto é, a diferenciação biológica entre homem e mulher assume uma conotação determinista que atribui naturalmente ao sexo feminino a tarefa de educar. 


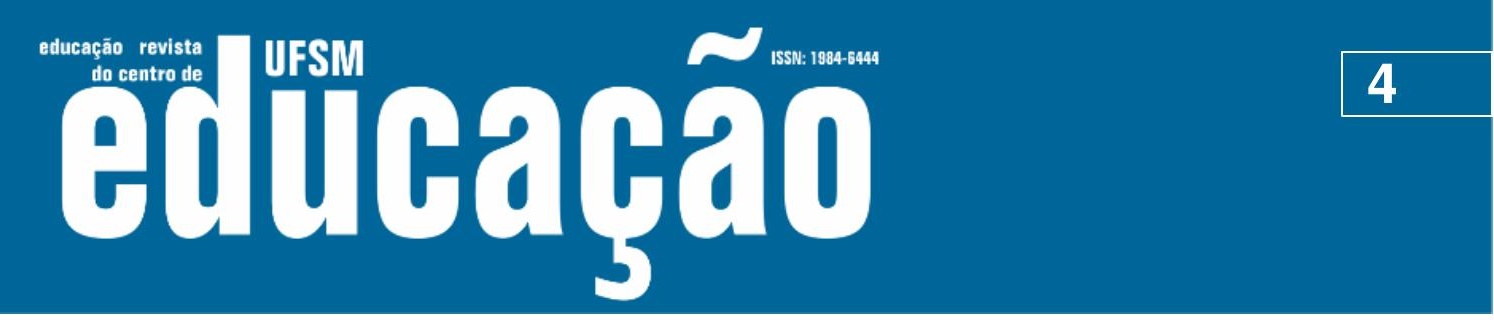

ISSN: 1984-6444 | http://dx.doi.org/10.5902/1984644440318

(ROSEMBERG, 2001, p. 515). E é nesse ponto que Fúlvia Rosemberg (2001) destaca a necessidade de ter cuidado ao analisar dados e políticas educacionais sobre a realidade de (in)sucesso de meninos e meninas a partir de uma matriz homogeneizante ou universalizante de "homem" e "mulher" universais.

A partir dos anos 2000, o alavancamento da sistematização e a produção de informações estatísticas concatenadas à uma política de publicização de dados pelo Instituto Nacional de Pesquisas Educacionais - INEP proporcionou os primeiros escrutínios quantitativos mais robustos dessas informações e, consequentemente, a corroboração dessa discussão. Pioneiramente, Gatti \& Barreto (2009) ao analisarem o perfil dos estudantes de licenciatura nos microdados do Exame Nacional de desempenho do Estudante - ENADE de 2005 constataram que naquele ano 75,4\% dos estudantes eram do sexo feminino, sendo o curso de pedagogia o que apresentava o valor mais expressivo, com 92,5\% de estudantes deste mesmo sexo.

No âmbito institucional, no ano de 2009 o INEP apresentou o "Estudo Exploratório do Professor Brasileiro" (INEP, 2009), que apresentou um amplo e detalhado panorama da profissão docente no Brasil através de uma série de variáveis distintas coletadas e escrutinadas a partir do senso da educação básica de 2007 corroborando as análises anteriores: há uma presença significativamente maior de mulheres nas salas de aulas do Brasil em todas as fases da educação básica, com exceção de algumas disciplinas do ensino médio. Como nos destaca Rosemberg (2001): corolários das diferenças de gênero ou reforçoda dominação de gênero?

O fato é que desse período até a atualidade, os estudos e levantamentos, sejam institucionais ou acadêmicos, tem corroborado a discussão em tela, isto é, a caráter feminino da sala de aula no Brasil, exemplo disso é o "Teacher and Learning Internacional Survey" de 2013, realizado pela Organização de Cooperação para o Desenvolvimento Econômico - OCDE que pesquisou o perfil de professores através de 31 países desenvolvidos e em desenvolvimento. De acordo com esse levantamento, no Brasil $71 \%$ dos professores em sala de aula são mulheres, um número superior à média dos países pesquisados, que foi de 68\% (OECD, 2013).

De todo modo, a despeito desses estudos, há um evidente estacionamento da discussão nas evidências quantitativas imediatas da questão: constata-se que há um 


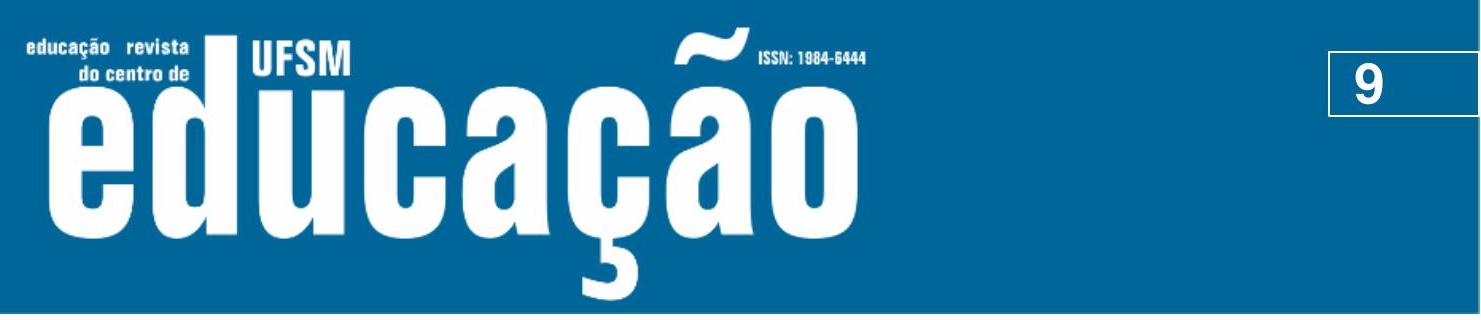

ISSN: 1984-6444 | http://dx.doi.org/10.5902/1984644440318

Dos 14 cursos de licenciatura avaliados no ENADE 2011, 50\% dos cursos apresentavam um percentual de mulheres superior ao correspondente na população Brasileira (tanto nas IES públicas quanto privadas), o que se traduz, no final, de $69 \%$ de mulheres nos cursos de licenciatura das IES públicas e de 78,6\% nas IES privadas. Contudo, a despeito dessa presença majoritária de mulheres, cursos com a Física e Computação, com maior saída no mercado de trabalho do Ensino Médio e consequentemente com um melhor salário, apresentam um número maior de homens do que de mulheres, evidenciando um aproveitamento pela população masculina de cursos que possuem uma saída mais bem remunerada no mercado de trabalho. Vale ressaltar que este perfil corrobora com a composição da classe docente no Brasil. Dados do Estudo Exploratório do Professor Brasileiro (INEP, 2009) evidenciam que a despeito do caráter esmagadoramente feminino da classe, no Ensino Médio (disciplinas especializadas) e no Ensino Técnico-Profissional, que sabidamente pagam os melhores salários, a discrepância quanto ao sexo dos estudantes é quase que insignificante, o que evidencia uma certa seletividade do sexo masculino por algumas carreiras da licenciatura.

Carvalho e Sobreira (2008) afirmam que as profissões e as áreas do conhecimento são definidas como "masculinas" ou "femininas". Dessa modo, engenharias, produção, construção, matemática e computação seriam "masculinas", enquanto educação, humanidades e artes seriam "femininas". Para Rosemberg (2001, p. 515) essa diferenciação é feita num nível até mesmo "independentemente do sexo das pessoas que as executam". O que faz, por exemplo, surgir um campo de resistências de mulheres que estudam e trabalham nos campos ditos "masculinos", e vice-versa (CARVALHO; SOBREIRA, 2008). Portanto, não é a autodeclaração do sexo que faz a docência ser feminina, mas um processo social de desvalorização e feminização da docência (SANTOS, 2005) e socialização de meninos e meninas a partir de um conceito universal de masculino e feminino (CARVALHO; SOBREIRA, 2008).

Ao se debruçar sobre a questão da renda, o panorama geral verificado em vasta literatura foi de que em termos de salário a profissão docente é uma profissão da classe trabalhadora, isto é, da classe economicamente menos favorecida (BRITO, 


\section{工 WFM

ISSN: 1984-6444 | http://dx.doi.org/10.5902/1984644440318

condição de renda mais precária. Para se ter ideia disto, basta observar que quando distribuímos a renda por sexo (f e m) os indivíduos do sexo masculino de cursos como o de Física (FSC-m), Ed. Física (EDF-m), Letras (LTR-m), Computação (CPÇ-m) e Geografia (GGF-m) associam à uma renda familiar maior do que a parte feminina da amostra.

Figura 3 - AC codificada interativa para a variável renda nas IES públicas $(A)$ e privadas (B).

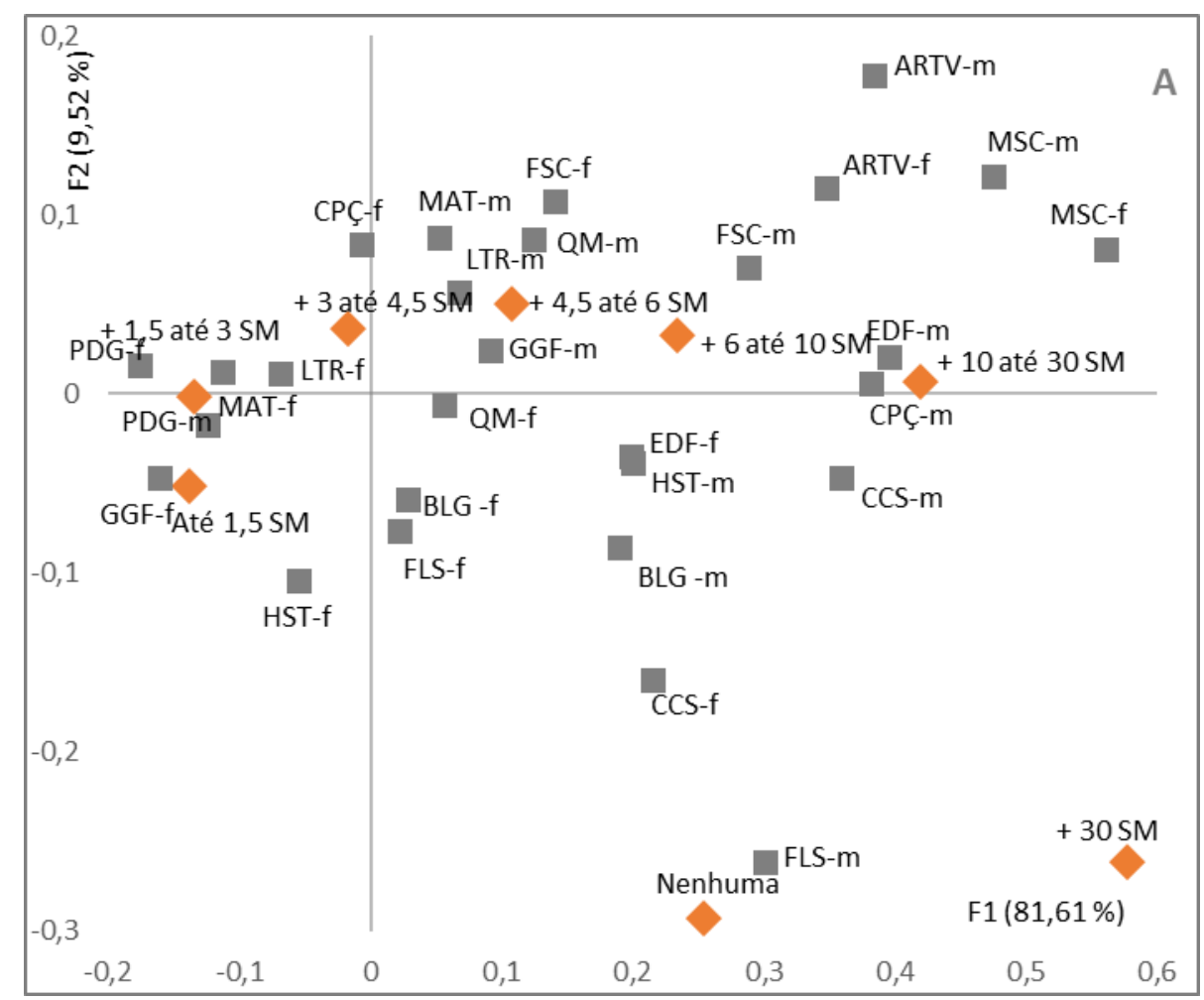

Fonte: Microdados do ENADE, elaboração dos autores (2020). 


\section{Uism

ISSN: 1984-6444 | http://dx.doi.org/10.5902/1984644440318

Figura 4 - AC codificada interativa para a variável renda nas IES públicas $(A)$ e privadas (B).

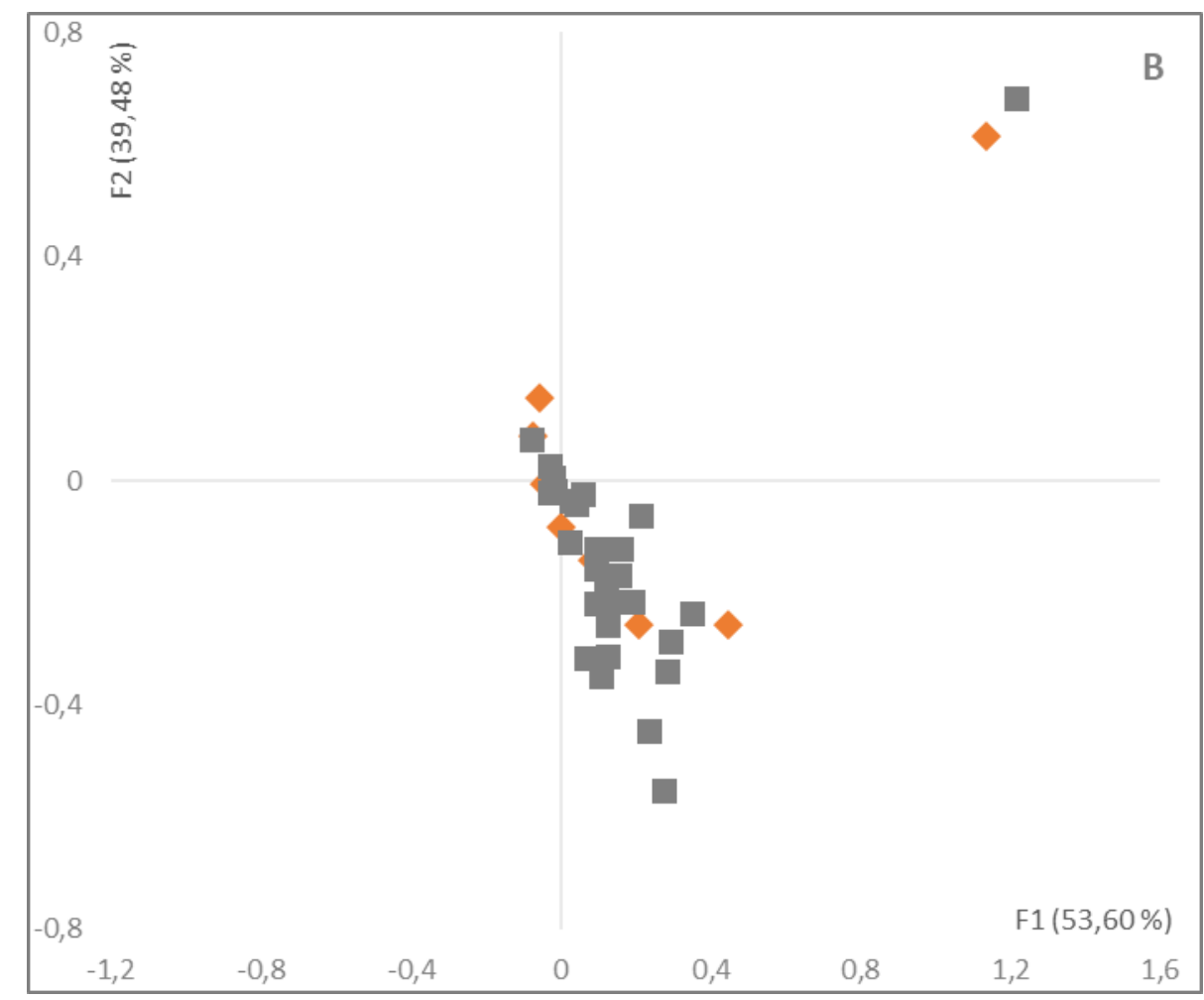

Fonte: Microdados do ENADE, elaboração dos autores (2020).

Do mesmo modo, enquanto a parte feminina da amostra do curso de Física (FSC-f) fica mais próximo do estrato de renda "mais de 4,5 até 6 mínimos" ( $+4,5$ até 6 $\mathrm{SM}$ ) a parte masculina da amostra (FSC-m) está mais próxima do estrato de renda "mais de 6 até 10 mínimos (+6 até $10 \mathrm{SM}$ ). Isto quer dizer que nestes cursos, os grupos de indivíduos que apresentam uma condição de renda maior do que a média do curso quando separados por sexo evidenciam que a renda familiar dos homens é maior do que das mulheres. Já no caso do curso de Ed. Física, enquanto a parte feminina do curso (EDF-f) não se associa muito definidamente a determinado estrato de renda, a parte masculina (EDF-m) da amostra se associa ao estrato de renda "mais de 10 até 30 mínimos" (+10 até $30 \mathrm{SM}$ ), isto é, dentre aqueles que apresentam uma maior renda no curso de educação física, a maioria é do sexo masculino. No caso do curso de letras, que é um curso de maioria feminina, enquanto a parte feminina da amostra (LTR-f) fica entre os estratos de renda "mais de 3 até 4,5 mínimos" (+3 até 4,5 SM) e 


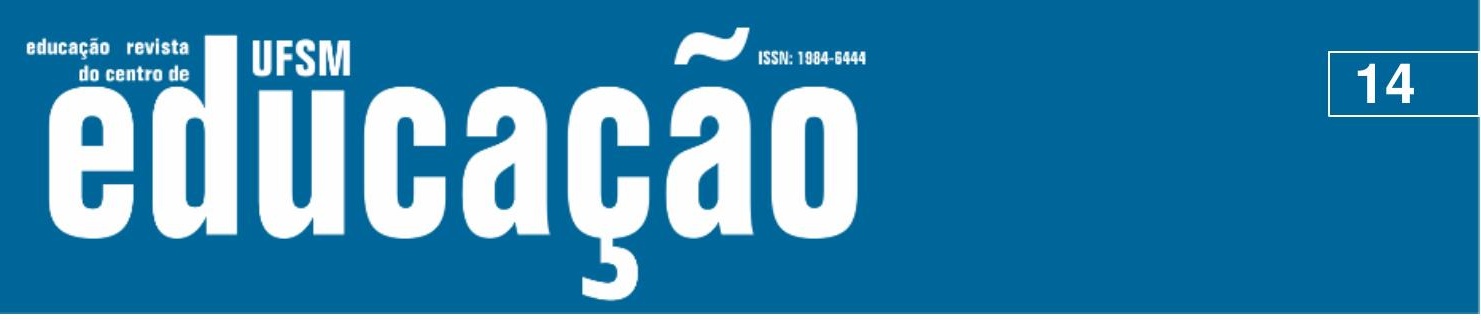

ISSN: 1984-6444 | http://dx.doi.org/10.5902/1984644440318

Yamed (2015), no Brasil as desigualdades salariais baseadas nas diferenças de gênero tendem a ser mais notáveis dentre aqueles mais escolarizados.

Nesse sentido, é com segurança que se infere que embora a amostra no todo seja esmagadoramente feminina (68,9\%), os trajetos a serem percorridos pelas mulheres são, em alguns casos, mais tortuosos: isto é, elas são oriundas de famílias com menor poder aquisitivo, o que reproduz com certa fidelidade a realidade nacional. Dados do Instituto de Pesquisa Econômica e Aplicada - IPEA sobre desigualdades de gênero e raça no Brasil indicam que quase 1/3 das famílias brasileiras são chefiadas por mulheres, ao passo que desse 1/3 aproximadamente 50\% dessas famílias são monoparentais (IPEA, 2015). Considerando este dado, pode se inferir também que boa parte das mulheres que compõem a amostra do estudo possuem grande possibilidade de serem chefes de família, o que torna a situação delas ainda mais desafiadora. Deste modo, ainda no tocante à renda, estes dados corroboram também, a partir desta inferência, que o micro espaço do campus das universidades públicas, lugar quem em tese deve produzir ciência e conhecimento e ajudar no progresso social reproduz, com certa fidedignidade, as desigualdades observadas fora desse seletivo espaço acadêmico, ainda que este seja majoritariamente ocupado por mulheres, como é o caso dos cursos de licenciatura. As teorias reprodutivistas ainda seriam uma maneira de explicar esse fenômeno, isto é, as condições de desigualdades sociais são reproduzidas nos sistemas de ensino (BOURDIEU; PASSERON, 1975)?

Saviani (1983), ao analisar as teorias da educação, faz uma ressalva quanto aquelas teorias, que ao seu ver são crítico-reprodutivistas. Afirma ele que por mais que essas teorias consigam destacar a violência simbólica que estrutura a dominação e é reproduzida pelos sistemas de ensino, não conseguem ultrapassar a dicotomia estado sociedade e sua inter-relação com a escola, cabendo a esta transmitir os subprodutos de uma cultura dicotomizada entre burguesia e proletariado. Por isso, ele propõe uma teoria crítica da educação que reconhece seu caráter histórico, as contradições do real e a reificação da estrutura social. O que demanda uma educação de qualidade, especialmente para dominados/as, para apropriação dos instrumentos culturais para superação da dominação. 


\section{usm

ISSN: 1984-6444 | http://dx.doi.org/10.5902/1984644440318

auxílios). Como podemos notar na figura 4A há uma clara distinção entre a parte feminina e masculina nos estudantes das IES públicas quando se considera esta variável. Pode-se deduzir isso quando se observa, a título de exemplo, que a parcela feminina dos cursos conjugados (destacados com um "f") se concentram no lado direito do gráfico, associados as categorias de trabalho eventual (eventual) e de não trabalho (não), ao passo que a parcela masculina da amostra se concentra do lado esquerdo do gráfico, ao lado das categorias de trabalho que vão de menos de 20 horas semanais (>=20h) até aqueles que trabalham quarenta horas semanais em tempo integral (TI, 40h).

Figura 5 - AC codificada interativa para a variável trabalho nas IES públicas $(A)$ e privadas (B).

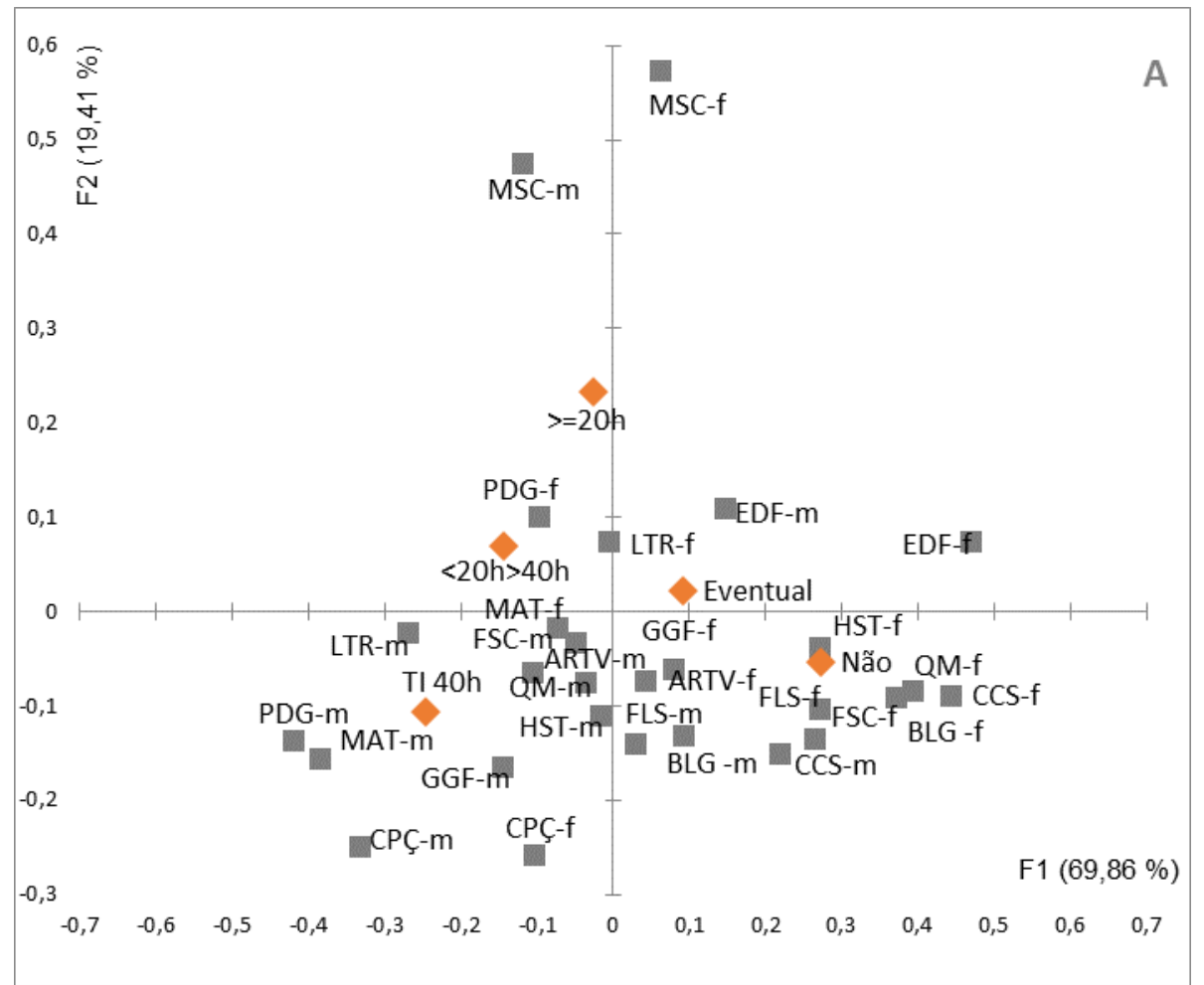

Fonte: Microdados do ENADE, elaboração dos autores (2020). 


\section{Trsm

ISSN: 1984-6444 | http://dx.doi.org/10.5902/1984644440318

Figura 6 - AC codificada interativa para a variável trabalho nas IES públicas $(A)$ e privadas (B).

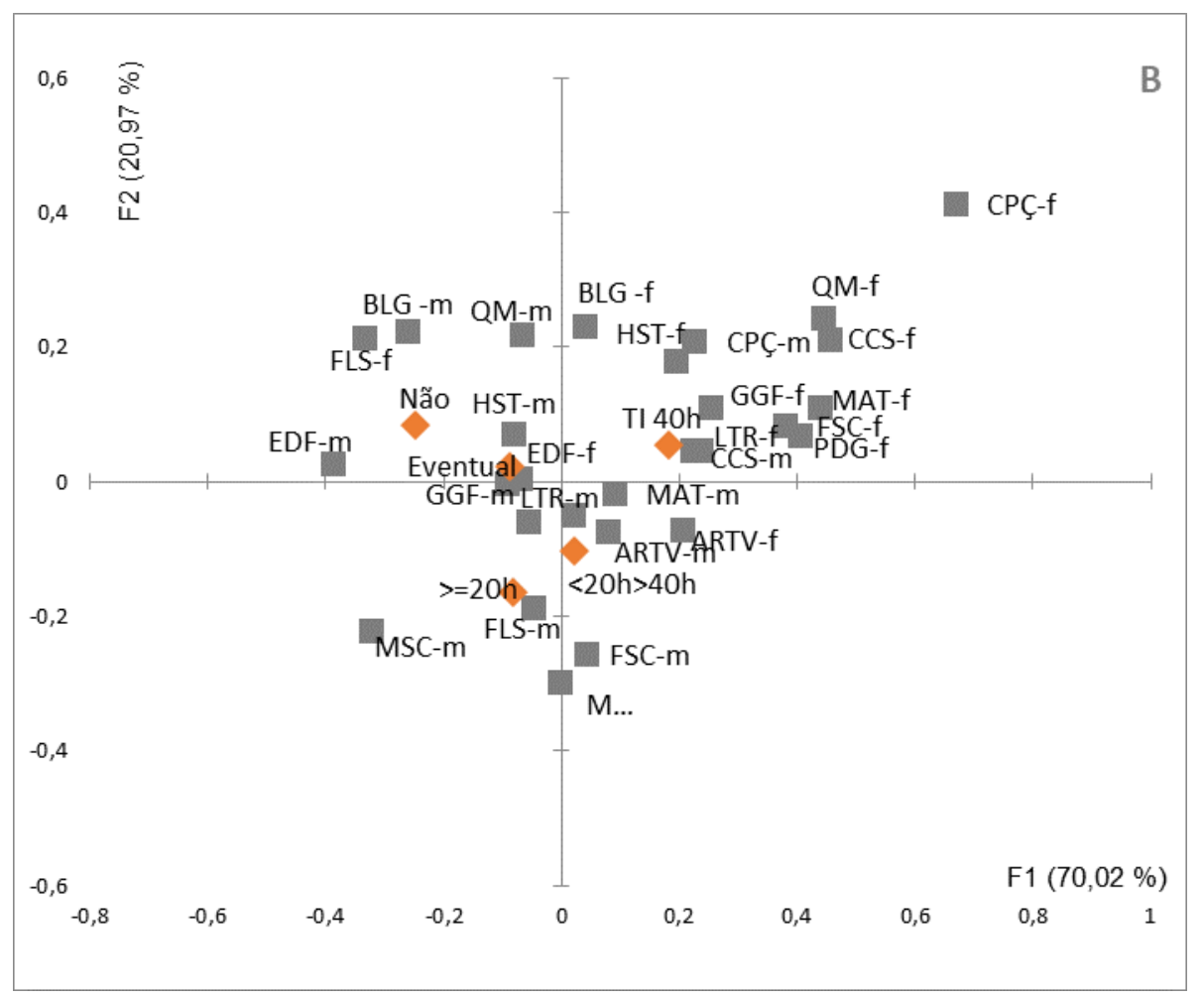

Fonte: Microdados do ENADE, elaboração dos autores (2020).

Estes dados sobre trabalho também corroboram mais uma vez uma discrepante realidade que perpassa as desigualdades de gênero no Brasil e que se reflete nas universidades públicas, como atesta o caso em tela. Apesar de mais escolarizadas, dados também do IPEA indicaram, que no ano da coleta dos dados utilizados nesse estudo, que para cada homem desempregado no Brasil, havia 1,73 mulher desempregada (IPEA, 2011). Do mesmo modo, este estudo também indica que além de serem as maiores vítimas do desemprego, as mulheres inseridas no mercado de trabalho enfrentam condições menos favoráveis, como a informalidade, algo mais ou menos dedutível nos dados apresentados, já que a parte feminina da amostra ("f") ficou mais próxima da categorial de trabalho "eventual", o que também pode indicar o trabalho eventual doméstico (ROSEMBERG, 2001), que apesar de constituir uma forma de trabalho não é reconhecido como tal. 


\section{تilloapẫ

ISSN: 1984-6444 | http://dx.doi.org/10.5902/1984644440318

Tabela 2 - Situação financeira das estudantes do sexo masculino que fizeram o ENADE nas IES públicas.

\begin{tabular}{|c|c|c|c|c|c|c|c|}
\hline \multirow{2}{*}{\multicolumn{2}{|c|}{ CURSOS }} & \multicolumn{6}{|c|}{ CATEGORIAS DE RESPOSTAS } \\
\hline & & A & $\mathrm{B}$ & $\mathrm{C}$ & $\mathrm{D}$ & $\mathrm{E}$ & TOTAL \\
\hline \multirow{2}{*}{ MATEMÁTICA } & $\mathrm{N}$ & 486 & 952 & 806 & 794 & 764 & 3.802 \\
\hline & $\%$ & $12,8 \%$ & $25,0 \%$ & $21,2 \%$ & $20,9 \%$ & $20,1 \%$ & $100,0 \%$ \\
\hline \multirow{2}{*}{ LETRAS } & $\mathrm{N}$ & 461 & 794 & 563 & 613 & 482 & 2.913 \\
\hline & $\%$ & $15,8 \%$ & $27,3 \%$ & $19,3 \%$ & $21,0 \%$ & $16,5 \%$ & $100,0 \%$ \\
\hline \multirow{2}{*}{ FÍSICA } & $\mathrm{N}$ & 195 & 438 & 292 & 244 & 208 & 1.377 \\
\hline & $\%$ & $14,2 \%$ & $31,8 \%$ & $21,2 \%$ & $17,7 \%$ & $15,1 \%$ & $100,0 \%$ \\
\hline \multirow{2}{*}{ QUÍMICA } & $\mathrm{N}$ & 189 & 381 & 180 & 198 & 118 & 1.066 \\
\hline & $\%$ & $17,7 \%$ & $35,7 \%$ & $16,9 \%$ & $18,6 \%$ & $11,1 \%$ & $100,0 \%$ \\
\hline \multirow{2}{*}{ BIOLOGIA } & $\mathrm{N}$ & 535 & 762 & 306 & 314 & 232 & 2.149 \\
\hline & $\%$ & $24,9 \%$ & $35,5 \%$ & $14,2 \%$ & $14,6 \%$ & $10,8 \%$ & $100,0 \%$ \\
\hline \multirow{2}{*}{ PEDAGOGIA } & $\mathrm{N}$ & 273 & 446 & 455 & 538 & 409 & 2.121 \\
\hline & $\%$ & $12,9 \%$ & $21,0 \%$ & $21,5 \%$ & $25,4 \%$ & $19,3 \%$ & $100,0 \%$ \\
\hline \multirow{2}{*}{ HISTÓRIA } & $\mathrm{N}$ & 647 & 919 & 517 & 501 & 294 & 2.878 \\
\hline & $\%$ & $22,5 \%$ & $31,9 \%$ & $18,0 \%$ & $17,4 \%$ & $10,2 \%$ & $100,0 \%$ \\
\hline \multirow{2}{*}{ ARTES VISUAIS } & $\mathrm{N}$ & 46 & 103 & 65 & 55 & 30 & 299 \\
\hline & $\%$ & $15,4 \%$ & $34,4 \%$ & $21,7 \%$ & $18,4 \%$ & $10,0 \%$ & $100,0 \%$ \\
\hline \multirow{2}{*}{ GEOGRAFIA } & $\mathrm{N}$ & 514 & 832 & 554 & 516 & 369 & 2.785 \\
\hline & $\%$ & $18,5 \%$ & $29,9 \%$ & $19,9 \%$ & $18,5 \%$ & $13,2 \%$ & $100,0 \%$ \\
\hline \multirow{2}{*}{ FILOSOFIA } & $\mathrm{N}$ & 183 & 222 & 165 & 131 & 105 & 806 \\
\hline & $\%$ & $22,7 \%$ & $27,5 \%$ & $20,5 \%$ & $16,3 \%$ & $13,0 \%$ & $100,0 \%$ \\
\hline \multirow{2}{*}{ ED. FÍSICA } & $\mathrm{N}$ & 599 & 1103 & 349 & 295 & 148 & 2.494 \\
\hline & $\%$ & $24,0 \%$ & $44,2 \%$ & $14,0 \%$ & $11,8 \%$ & $5,9 \%$ & $100,0 \%$ \\
\hline \multirow{2}{*}{ COMPUTAÇÃO } & $\mathrm{N}$ & 54 & 89 & 57 & 63 & 38 & 301 \\
\hline & $\%$ & $17,9 \%$ & $29,6 \%$ & $18,9 \%$ & $20,9 \%$ & $12,6 \%$ & $100,0 \%$ \\
\hline \multirow{2}{*}{ MÚSICA } & $\mathrm{N}$ & 64 & 198 & 112 & 97 & 66 & 537 \\
\hline & $\%$ & $11,9 \%$ & $36,9 \%$ & $20,9 \%$ & $18,1 \%$ & $12,3 \%$ & $100,0 \%$ \\
\hline \multirow{2}{*}{ CIÊNCIAS SOCIAIS } & $\mathrm{N}$ & 158 & 222 & 96 & 93 & 37 & 606 \\
\hline & $\%$ & $26,1 \%$ & $36,6 \%$ & $15,8 \%$ & $15,3 \%$ & $6,1 \%$ & $100,0 \%$ \\
\hline \multirow{2}{*}{ TOTAL } & $\mathrm{N}$ & 4.404 & 7.461 & 4.517 & 4.452 & 3.300 & 24.134 \\
\hline & $\%$ & $18,2 \%$ & $30,9 \%$ & $18,7 \%$ & $18,4 \%$ & $13,7 \%$ & $100,0 \%$ \\
\hline
\end{tabular}

Fonte: Microdados do ENADE, elaboração dos autores (2020).

É conclusivo pois, considerar que mesmo em maior número, as futuras professoras enfrentam desafios socioeconômicos bem mais robustos do que seus colegas do sexo masculino. Insistimos mais uma vez, portanto, na evidência de um paradoxo. Embora o fato de não trabalhar - ou melhor dizendo, de trabalharem em menor número e com cargas horárias menores - possa representar melhores condições de formação dessas futuras professoras, sendo isto atestado por uma maior média de anos de escolaridade no mercado de trabalho isto é, de dedicação 


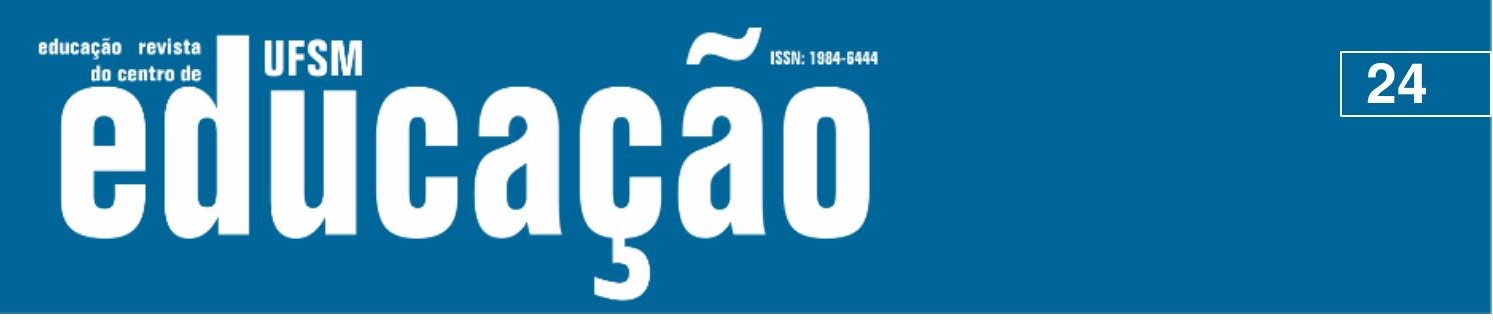

ISSN: 1984-6444 | http://dx.doi.org/10.5902/1984644440318

sistema co-intencional do que naturalmente posto. Nesse sentido partimos da premissa de que esse processo se dá como forma de desvalorização da profissão e rebaixamento salarial como processo da Modernidade. Nesse sentido, conclui-se que precisamos vencer esse pelo escrutínio do pensamento crítico em suas mais diferentes nuances, isto é: conjugar análise, compreensão e ação em um mesmo processo e espaço.

\section{Referências}

AGENOR, Pierre-Richard; CANUTO, Otaviano;. Gender equality and economic growth in Brazil: A long-run analysis. Journal of Macroeconomics, Athens (Georgia), v.43, s/n, p.155-172, 2015.

APPLE, Michael Whitman. Controlando o trabalho docente. In:APPLE, M. W. Trabalho docente e textos: economia política de classe e gênero em educação. Porto Alegre: Artemédicas, 1995. P.31-81

BRAVERMAN, Harry. Part V: the working class. In:BRAVERMAN, Hrarry. Labor and monopoly capital: the degradation of work in the twentieth century. New York: Monthly Review Press, 1998. p. 261-294.

BRITO, Márcia Regina Ferreira. ENADE 2005: perfil, desempenho e razão da opção dos estudantes pelas Licenciaturas. Avaliação, Campinas, v.12 n.3, p.135-158, 2007.

BRITTO, Ariana Martins de.; WALTENBERG, Fabio. É atrativo tornar-se professor do Ensino Médio no Brasil? Evidências com base em decomposições paramétricas e não-paramétricas. Estudos Econômicos, São Paulo, v. 44, n.1, p. 5-44, jan.-mar. 2014.

BOURDIEU, Pierre.; PASSERON, Jean-Claude. A reprodução: elementos para uma teoria do sistema de ensino. Rio de Janeiro: Francisco Alves, 1975.

CARVALHO, Maria Eulina Pessoa de; RABAY, Glória. Usos e incompreensões do conceito de gênero no discurso educacional brasileiro, Estudos Feministas, Florianópolis, v. 23, n. 1, jan./abr. 2015.

CARVALHO, Marilia Gomes de; SOBREIRA, Josimeire de Lima. Gênero nos cursos de engenharia de uma universidade tecnológica brasileira. ARBOR Ciencia, Pensamiento y Cultura, n. 733, 2008.

CARVALHO, Marília; STRUNCHINER, Cláudio José. Análise de Correspondência: Uma aplicação do método à avaliação de serviços de vacinação. Caderno de Saú de Pública, Rio de Janeiro, Vol. 8, n. 3, pp. 287301, jul/set. 1992. 


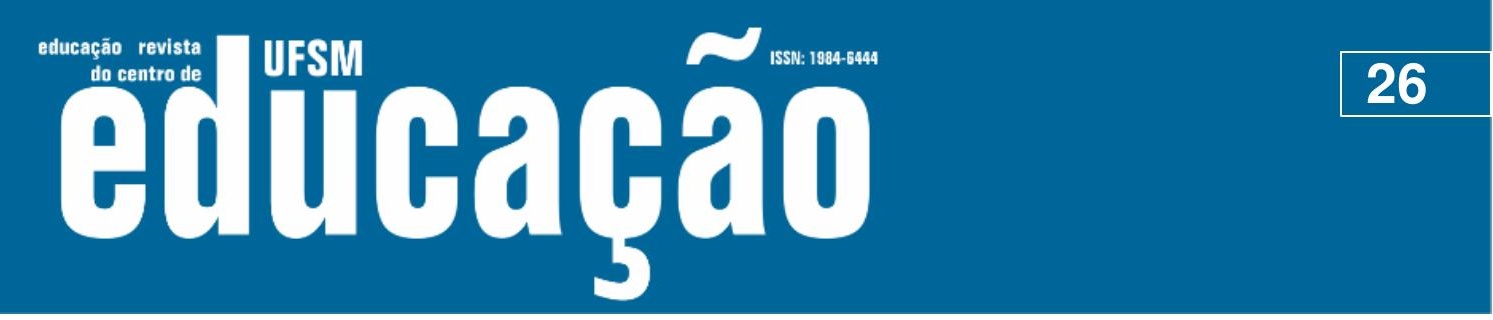

ISSN: 1984-6444 | http://dx.doi.org/10.5902/1984644440318

LOUZANO, Paula:; ROCHA, Valéria:; MORICONI, Gabriela; OLIVEIRA, Romualdo Portela. Quem quer ser professor? Atratividade, seleção e formação docente no Brasil. Est. Aval. Educ., São Paulo, v. 21, n. 47, p. 543-568, set./dez. 2010.

LÜDKE, Menga; ANDRÉ, Marli. Pesquisa em educação: abordagens qualitativas. São Paulo: EPU, 1986.

MAIA, Marcos Felipe Gonçalves; ROCHA, José Damião Trindade. A fenomenologia na pesquisa em educação: um olhar sobre a etnometodologia e a etnopesquisa crítica.

Atos de Pesquisa em Educação, Blumenau, v. 11, n. 3, 2016.

MAIA, Marcos Felipe Gonçalves; ROCHA, José Damião Trindade. Ideologia de gênero: tensões e desdobramentos na educação. Revista Contemporânea de Educação, v. 12, n. 25, 2017.

MERLEAU-PONTY, Maurice. Fenomenologia da percepção. São Paulo: Martins Fontes, 1999.

NUNES, Daniel Freitas. Quem quer ser professor no Brasil: uma análise a partir de variáveis socioeconômicas de estudantes de licenciatura. 2015. xiv, 126 f., il. Dissertação (Mestrado em Educação) - Universidade de Brasília, Brasília, 2015.

Organisation for Economic Co-operation and Development - OECD. TALIS 2013 Results: An International Perspective on Teaching and Learning. Paris: OECD Publishing, 2014.

PONTHIEUX, Sophie; MEURS, Dominique. Gender Inequality. In: ATKINSON, Anthony; BOURGUIGNON, Francois (Orgs.). HandbookoflncomeDistribution. Amsterdam: Elsevier, p.983-1119.

RISTOFF, Dilvo Ivo. Perfil socioeconômico do estudante de graduação: uma análise de dois ciclos completos do Enade (2004 a 2009). Rio de Janeiro: Flacso/Brasil - Cadernos do GEA, n. 4, jul./dez. 2013.

ROSEMBERG, Fulvia. Educação formal, mulher e gênero no Brasil contemporâneo. Estudos Feministas, v. 9, n. 2, p. 515-540, 2001.

ROSEMBERG, Fulvia; e AMADO, Tina. Mulheres na Escola. Cadernos de Pesquisa, São Paulo, s/v, n. 80, fevereiro de 1992, pp.62-74.

SALATA, André. Ensino superior no Brasil das últimas décadas: redução das desigualdades de acesso. Tempo Social, v. 30, n. 2, maio/ago. 2018.

SANTOS, Boaventura. Pela mão de Alice: o social e o político na pós-modernidade. São Paulo: Cortez, 2005.

SABATINE, Thiago Teixeira; FODRA, Sandra Maria. Gênero, sexualidade e diversidade sexual no contexto das políticas públicas educacionais do estado de são Paulo. Café com Sociologia, v. 7, n. 1, p. 11-29, jan./abr. 2018. 


\section{uss \\ 7 ISSN: 1984-6444

ISSN: 1984-6444 | http://dx.doi.org/10.5902/1984644440318

SAVIANI, Demerval. Escola e democracia. Campinas, SP: Autores Associados, 1983.

SCOTT, Joan. Gênero: uma categoria útil de análise histórica. Educação \& Realidade, vol. 20, n. 2, jul./dez. 1995.

SILVA, Marjorie Cristina Rocha da; VENDRAMINI, Claudettte Maria Medeiros; LOPES, Fernanda Luzia. Diferenças entre gênero e perfil socioeconômico no exame nacional de desempenho do estudante. Avaliação, vol.15, n.3, p. 185-202, 2010.

VIANNA Cláudia Pereira. O sexo e o gênero da docência. Cadernos Pagu. São Paulo, s/v, n.80, p. 81-103, 2002.

YAHMED, Sarra Ben. Formal but Less Equal: gender Wage Gaps in Formal and Informal Jobs in Urban Brazil. World Development, Michigan, v. 101, s/n, p-58-69, 2015.

\section{Correspondência}

Daniel de Freitas Nunes - Instituto Federal Goiano - Rodovia Go-154, Km 03, s / n, CEP 76300-000, Ceres, Goiás, Brasil.

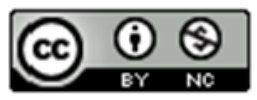

This work is licensed under a Creative Commons Attribution-NonCommercial 4.0 International (CC BY-NC 4.0)

\section{Notas}

\footnotetext{
${ }^{1}$ Categorias de Respondentes: $\mathrm{A}=$ não tenho renda e meus gastos são financiados por outras pessoas; $\mathrm{B}=$ tenho renda, mas recebo ajuda para financiar meus gastos; $\mathrm{C}=$ tenho renda e me sustento totalmente; $\mathrm{D}=$ tenho renda, me sustento e contribuo com o sustento da família; $\mathrm{E}=$ tenho renda, me sustento e sou o principal responsável pelo sustento da família.
} 